\title{
Cardiooncology—dealing with modern drug treatment, long-term complications, and cancer survivorship
}

\author{
Claudia de Wall $^{1} \cdot$ Johann Bauersachs $^{1} \cdot$ Dominik Berliner $^{1}$ (I)
}

Received: 4 January 2021 / Accepted: 28 May 2021 / Published online: 12 June 2021

(c) The Author(s) 2021

\begin{abstract}
Modern treatment strategies have improved prognosis and survival of patients with malignant diseases. The key components of tumor treatment are conventional chemotherapy, radiotherapy, targeted therapies, and immunotherapy. Cardiovascular side-effects may occur in the early phase of tumor therapy or even decades later. Therefore, knowledge and awareness of acute and long-lasting cardiac side effects of anti-cancer therapies are essential. Cardiotoxicity impairs quality of life and overall survival. The new cardiologic subspecialty 'cardio-oncology' deals with the different cardiovascular problems arising from tumor treatment and the relationship between cancer and heart diseases. Early detection and treatment of cardiotoxicity is of crucial importance. A detailed cardiac assessment of patients prior to administration of cardiotoxic agents, during and after treatment should be performed in all patients. The current review focusses on acute and long-term cardiotoxic side effects of classical cytotoxic and selected modern drug treatments such as immune checkpoint inhibitors and discusses strategies for the diagnosis of treatment-related adverse cardiovascular effects in cancer patients.
\end{abstract}

Keywords Cardio-oncology · Cardiotoxicity $\cdot$ Myocardial dysfunction · Cancer survivorship · Long-term complications · Chemotherapy

\section{Introduction}

Advances in the early detection of malignant diseases and modern treatment strategies have improved prognosis and survival of cancer patients [1]. Cardiovascular morbidity and mortality is increased in those patients due to pathophysiological processes in connection with the cancer itself, patient initial comorbidities, and toxicity of anticancer therapies making cardiovascular diseases in those patients a leading cause of death after cancer itself [2-4]. As patients with malignant diseases have been largely excluded from randomized controlled clinical trials in cardiology during the past decades evidence on diagnostics, treatment and monitoring strategies is scarce [5]. In contrast, respective treatment strategies based on multiple randomized trials exist in non-cancer patients, emphasizing the need for further cardiovascular research in cancer patients and justifying the relevance of cardio-oncology. The development of

Dominik Berliner

berliner.dominik@mh-hannover.de

1 Dept. of Cardiology and Angiology, Hannover Medical School, Carl-Neuberg-Str. 1, 30625 Hannover, Germany new oncological therapeutic agents that specifically influence the central signaling pathways of tumor cells has led to the approval of many new drugs in recent years. In parallel, there are also several reports of cardiovascular side effects. Therefore, the interaction between cardiology and oncology is becoming increasingly important.

Cancer related cardiovascular complications may manifest acutely within days, weeks, or months but also chronically years after the initial treatment. Due to a better precision of modern treatment strategies, physicians are confronted with an increasing number of adult survivors of childhood, adolescent and young adult cancer. Long-term toxicity in this patient group has been reported to be up to 60-70\% [6]. Well-structured cancer survivorship programs are of crucial importance to continuously monitor patients with increased life-time risk for morbidity and mortality.

In the last years cardiooncology has emerged as a new field in cardiology targeting on more evidence in the pathophysiology, diagnostics, and treatment of acute and longterm cardiotoxic effects of (modern) cancer treatment strategies.

Online databases (MEDLINE, PubMed) were searched for recent studies and reviews evaluating the cardiac side 
effects in cancer patients. The following keywords were used: cardiotoxicity, chemotherapy, immune check point inhibitors, radiation therapy, cancer survivors, myocardial dysfunction. Potentially relevant citations were retrieved from reference lists of the identified reports and relevant reviews. We consider the cardiac side effects of conventional cytotoxic chemotherapy, antibodies targeting immune checkpoints, and radiotherapy. In the current review molecular therapies targeting signal transduction are not discussed.

\section{Cardiovascular side effects of clinically selected anti-cancer therapies}

The clinical spectrum of cardiovascular complications is broad and ranges from heart failure and cardiomyopathy over valve diseases, myocardial ischemia, pericardial diseases, and hypertension to arrhythmias and thromboembolic complications (Fig. 1). Cardiomyopathy and heart failure are the most common and often most limiting manifestations [7]. Actually, there is no single and universally accepted definition of cancer treatment related cardiotoxicity [5]. Several medical societies have introduced different definitions of cardiotoxicity (Table 1) [8-10].

In 2014, the European Association of Cardiovascular Imaging and the American Society of Echocardiography presented a concordant consensus defining cancer therapeutics-related cardiac dysfunction (CTRCD) as a decrease in the left ventricular ejection fraction (LVEF) of $>10$ percentage points to the value $<53 \%$ (normal reference value of two-dimensional echocardiography). This decrease should be confirmed by repeated cardiac imaging 2 to 3 weeks later [11].

Based on the underlying pathophysiological mechanism, CTRCD has been classified into two types [11]:

1. Type I CTRCD is caused primarily by anthracyclines and leads to cell apoptosis and therefore to an irreversible myocardial cell damage. The effect is dose dependent.

2. Type 2 CTRCD is caused by several different agents (e.g. trastuzumab), is not dose dependent, does not lead to apoptosis by itself and therefore may be reversible.

It has to be mentioned that this strict classification in type 1 and type 2 CTRCD is more historic and no longer followed since overlapping outcomes are reported for the two chemotherapeutic classes.

The timing of cardiovascular side effects can vary among agents. In anthracyclines, the damage occurs immediately after exposure [12]. Data from a trial in which 2625 patients with anthracycline-based chemotherapy were enrolled showed an occurrence of cardiotoxicity within the first 12 months after treatment in $98 \%$ of patients [13]. In contrast, cyclophosphamide-associated heart failure which is
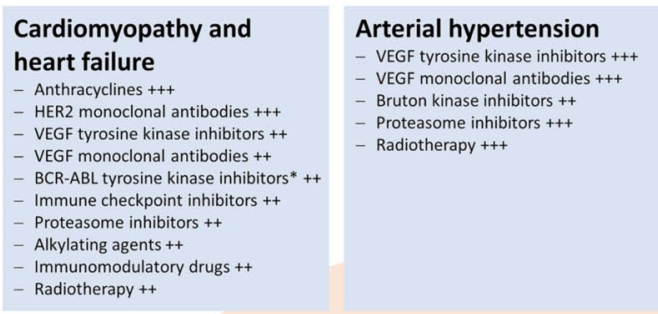

\section{Coronary artery disease} Fluoropyrimidines (spams +++, thrombosis ++) Alkylating agents ++
VEGF tyrosine kinase inhibitors ++ VEGF monoclonal antibodies ++ Immunomodulatory drugs ++ Radiotherapy +++

\section{Arrhythmias}

- Anthracyclines +
- Bruton kinase inhibitors ++ - Bruton kinase inhibitors

- Immunomodulatory drugs ++

\section{Cardiovascular complications of cancer treatment}

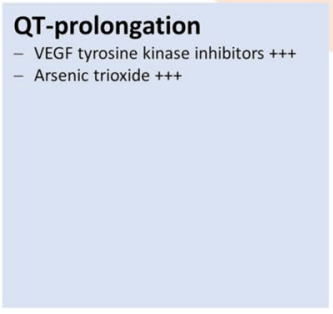

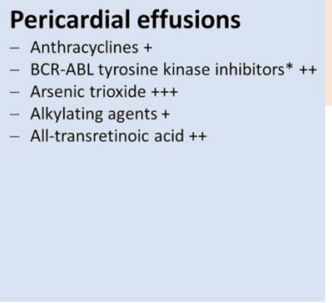

Pericardial constriction BCR-ABL tyrosine kinase inhibitors* ++ Radiotherapy ++

Pulmonary hypertension Proteasome inhibitors ++ - Alkylating agents +
Fig. 1 Cardiovascular complications of modern cancer treatment and the associated risk (* drug-dependent risk; + treatment associated with $<1 \%$ to develop the form of cardiotoxic side effect, ++ risk estimated to be between 1 and $10 \%,+++$ risk estimated to be $>10 \%$; adapted from $[64,86])$. For further information, the consensus paper of the European Society for Medical Oncology (ESMO) on "Man- agement of cardiac disease in cancer patients throughout oncological treatment" gives a comprehensive overview of the adverse cardiovascular side effects of the different drug classes as well as their different, specific agents while referring to respective key data and publications (Supplementary Table S1; [86]) 
Table 1 Different definitions of cardiotoxicity across organizations

\begin{tabular}{llll}
\hline Area of expertise & Medical Society & Region & Definition of cardiotoxicity \\
\hline Cardiology & DGK & Germany & Asymptomatic or symptomatic LVEF fall by $>10 \%$ from baseline to LVEF $<50 \%$ \\
& ESC & Europe & Asymptomatic or symptomatic LVEF fall by $>10 \%$ from baseline to LVEF $<50 \%$ \\
& CCS & Canada & LVEF fall by $>10 \%$ from baseline or LVEF $<53 \%$ \\
Cardiology_Imaging & EACVI & Europe & LVEF fall by $>10 \%$ to absolute LVEF $<53 \%$ \\
& ASE & United States & LVEF fall by $>10 \%$ to absolute LVEF $<53 \%$ \\
Oncology & ESMO & Europe & Symptomatic decline in LVEF of at least 5\% to $<55 \%$ or asymptomatic decline in \\
& NCI & United States & LVEF of at least $10 \%$ to $<55 \%$ \\
& & Common Terminology Criteria for Adverse Events: \\
& & & Heart Failure grade $1-5 *$ \\
\hline
\end{tabular}

ASE American Society of Echocardiography, CCS Canadian Cardiovascular Society, DGK Deutsche Gesellschaft für Kardiologie (German Society of Cardiology), EACVI European Association of Cardiovascular Imaging, ESC European Society of Cardiology, ESMO European Society of Medical Oncology, LVEF left ventricuar ejection fraction, NCI National cancer Institute; *Grade 1 (asymptomatic), Grade 2 (mild to moderate symptoms), Grade 3 (symptomatic on minimal exertion or at rest), Grade 4 (life-threatening), Grade 5 (death); adapted from [5, 11, 14, 76, 84, 85]

dose-dependent develops typically within 7 to 10 days after the application of high dose regimens [14]. Coronary artery vasospasm caused by fluoropyrimidines (5-FU) also occurs in the early phase of treatment. Cardiac events are typically short-lasting (up to $48 \mathrm{~h}$ ) and tend to manifest within 2 to 5 days after initiation of 5-FU [15]. Two studies that assessed the timing of cardiotoxicity in trastuzumab treated patients suggest that the first 3 months of treatment are the most precarious ones, counting for most of the cardiotoxic events, and that cardiotoxicity occurring more than 6 months after start of trastuzumab is rare [16, 17]. Similarly, most cases of ICI-induced myocarditis occur in the first three months following the start of treatment [18]. In this context, a special group of patients should be emphasized: There is evidence that pregnancy subsequent to childhood malignancy and chemotherapy poses a risk for peripartum cardiomyopathy [19]. Since pregnancy may be an increased risk factor for developing cardiomyopathy in patients who have previously been exposed to anthracyclines and/or radiation, an assessment of the cardiovascular risk in these patients should be carried out before pregnancy or in the first few weeks of pregnancy [20].

\section{Radiation leading to cardiac side effects}

Cardiac problems caused by thoracic radiation or following cancer therapy in childhood can manifest several decades later. Cardiovascular morbidity and mortality in childhood cancer survivors is mainly associated with anthracyclinetreatment and radiation of the chest [21-24]. In this context it has to be emphasized that until now, systematic analyses only exist for those two treatments and long-term studies for all newer modalities are lacking. In computed tomography angiography, nearly $40 \%$ of childhood cancer survivors had coronary lesions more than 20 years after cancer treatment
[25]. In this group of patients, development of cardiovascular risk factors should be closely monitored and stress testing (e.g. stress echocardiography, scintigraphy) even discussed in asymptomatic cancer survivors [26]. Typical chronic complications associated with radiotherapy include pericarditis, coronary artery disease, calcific valvular lesions, and myocardial fibrosis with mainly diastolic dysfunction [5, 27]. Chronic pericarditis is one of the most frequent radiationinduced cardiac side effects and also occurs following lowdose radiation [28]. Twenty percent of patients with chronic pericarditis develop a clinically relevant cardiac constriction. Among breast cancer patients who received radiation, coronary artery disease is the most frequent cardiovascular complication. Patients have an increased risk of developing coronary artery disease more than 20 years after radiotherapy $[29,30]$. However, all patients should be advised to be aware of the potential for acute and chronic cardiac complications and report symptoms (e.g. fatigue, shortness of breath, edema) to their health care provider.

\section{Immune checkpoint inhibitors and cardiovascular side effects}

Immune checkpoint inhibitors (ICI) are a novel class of drugs in systemic cancer treatment. ICI have been developed to restore the $\mathrm{T}$ cell-mediated immune response and improve the efficacy of anti-tumor treatments [31, 32]. Despite their excellent therapeutic effects, ICI may result in a broad spectrum of autoimmune-mediated side effects such as myocarditis [33, 18, 34-36]. In addition, the side effects can also manifest as arrhythmias (supraventricular and ventricular), conduction disorders with higher-grade blocks, but also acute myocardial ischemia, non-inflammatory cardiomyopathy, Tako-Tsubo syndrome, and pericarditis [37]. The mechanism of ICI-related cardiotoxicity is 
not yet fully understood. An autoimmune reaction against myocardial antigens is the assumed underlying pathomechanism in these patients. Autoantibodies against cTnT were observed in a patient with fatal Pembrolizumab-mediated myocarditis [38]. Bockstahler et al. proposed a potential mechanism where self-tolerance is abrogated by PD-1/ PD-L1 blockade. Tissue damage releases self-antigens such as cardiac troponin from cardiomyocytes and antigen presentation by dendritic cells and inflammatory cytokines can lead to increased self-reactive CD4+ T-cells [39]. ICI-induced myocarditis occurs at a frequency of 1-2\% and is associated with a relatively high mortality rate of $43-46 \%$. Most cases of ICI-induced myocarditis occur in the first three months following the start of treatment [18] and more than $90 \%$ of patients show increased troponin levels [34]. Due to the potential severity of myocarditis, further diagnostics should be performed immediately if ICI-induced myocarditis is suspected, and ICI should be stopped. An ischemic aetiology or other underlying causes of the increase in troponin must be excluded. Recently, Mirabel et al. described a case of lateonset giant cell myocarditis due to enterovirus in a patient on long-term ICI therapy [40]. If myocarditis is confirmed (MRI or biopsy), glucocorticoids are considered as first line treatment (initially $1-2 \mathrm{mg} / \mathrm{kg}$ prednisolone, alternatively $1 \mathrm{~g}$ methylprednisone in non-responders) [41]. If corticosteroids are insufficient or if instability persists other immunosuppressants, including mycophenolate mofetil, tacrolimus, infliximab (note: infliximab is contraindicated at high doses in patients with heart failure [42]), antithymocyte globulin, or intravenous immunoglobulin and plasmapheresis can be used as second line options [43]. Recently, treatment with the CTLA-4 agonist abatacept has been shown to be successful in treating a patient with of severe, glucocorticoidrefractory ICI-induced myocarditis [44]. Abatacept is an inhibitor of T cell activation by blocking CD80 and CD86 and has originally been approved for the treatment of rheumatoid arthritis. A clinical study on using abatacept in the treatment of patients with ICI-associated myocarditis is currently being planned [43].

\section{Baseline risk assessment in cardiooncology}

In the last years, several factors that significantly increase the risk for cardiotoxic effects in patients undergoing cancer therapy have been identified. Classical cardiovascular risk factors, preexisting cardiac disease, and previous cardiotoxic cancer treatment predispose to cardiovascular complications due to cancer therapy. Available data in this context is primarily based on anthracyclines and HER2-inhibitors and no strong data on other cardiotoxic drugs exists. The risk of developing cardiovascular side effects is generally higher in the younger (aged $<18$ years) and older population (aged
$>65$ years) and further increases in the presence of two of the following conditions: diabetes mellitus, hyperlipidemia, arterial hypertension, obesity, and smoking [21, 45-49]. So those factors should be acknowledged prior to the initiation of a specific therapy and modifiable risk factors should be optimized (e.g. treatment of hypertension prior to starting VEGF inhibitors). Furthermore, radiation increases the risk of cardiotoxic effects of certain chemotherapeutic agents (e.g. anthracyclines)[50]. Exposure to high doses of radiation (>30 Gy), anterior or left chest irradiation location, and the absence of shielding designate highest risk for radiationinduced heart disease [51].

Recently, the Heart Failure Association of the European Society of Cardiology together with the International Cardio-Oncology Society have emphasized the meaning of baseline risk assessment in cancer patients and proposed recommendations and a new risk assessment tool for patients planned to be treated with potentially cardiotoxic cancer therapies [52].

\section{Diagnostics and monitoring in cardiooncology}

To monitor cardiovascular complications associated with cancer treatment, onco-cardiological assessment should include patient's history, physical examination, electrocardiogram (ECG), echocardiography and biomarkers (e.g. troponins and natriuretic peptides). The ideal strategy for detection of cardiotoxicity is to compare measurements during cancer therapy with those obtained before initiation of the therapy. The identification of concomitant cardiovascular diseases is central in risk assessment. Patient's history and physical examination can help to identify pre-existing heart failure and atherosclerotic manifestations.

\section{Detecting cardiotoxicity—the impact of imaging}

Echocardiography plays a crucial role in the diagnosis of cardiotoxicity [53]. The current recommendations endorse the modified biplane Simpson's technique by two-dimensional (2D) echocardiography as the standard method for left ventricular ejection fraction (LVEF) determination [11]. The drawback of this method lies in its reproducibility-the test-retest variability in LVEF measurement using 2D echocardiography is up to $10 \%$ [54]. For this reason, the sensitivity for the detection of small changes in LV function is low which weakens the strength of this method for serial measurements. Three-dimensional (3D) echocardiography offers a more precise way of measuring left ventricular volumes and therefore LVEF [55] and has been shown to have less variability in the measurements compared to the $2 \mathrm{D}$ methods [54]. Hence, 3D echocardiography should be used for serial monitoring of cardiac effects of chemotherapy whenever possible. The recommendations for chamber quantification 
from ASE and EAE established a LVEF $\geq 52 \%$ for men and $54 \%$ for women as a normal reference range [56]. A LVEF of $50-55 \%$ is borderline low and considered as a high risk for potential cardiotoxic effects of chemotherapy [57]. Deterioration of left ventricular ejection fraction (LVEF) appears to be a relatively late marker [58]. Calculation of global longitudinal strain (GLS) by two-dimensional speckle tracking echocardiography is more sensitive in the detection of subclinical LV dysfunction [59,60]. GLS is a dimensionless measure of myocardial deformation that is analyzed by post-processing of apical images of the left ventricle using dedicated applications. A recent study has shown better interobserver agreement of GLS than for LVEF in patients undergoing potentially cardiotoxic chemotherapy [61]. A relative percentage reduction in GLS of $>15 \%$ is very likely to be abnormal [11]. Current guidelines recommend the comparison of GLS measured during chemotherapy cycles with baseline GLS values [11, 57]. Most of the data on the usefulness of GLS in predicting cardiotoxicity derive from therapies with anthracyclines or trastuzumab [62]. However, recently a study has shown the impact of changes in GLS also in the context of ICI-mediated myocarditis [63]. However, the gold standard of evaluation of left ventricular ejection fraction, volume and masses still remains cardiac magnetic resonance imaging (MRI). Cardiac MRI provides superior reproducibility of LVEF and the detection of small changes in LVEF and volumes compared to echocardiography [64], allowing tissue characterization of myocardial edema, inflammation and fibrosis. Its impact in the field of early detection of cardiotoxicity is increasing $[65,66]$. In this context, novel MRI indices are currently being investigated and represent promising approaches for an earlier detection of cardiotoxicity in the future [67]. Nevertheless, the use cardiac MRI in clinical practice is limited by costs and limited availability.

\section{Biomarkers and cardiotoxicity}

Several biomarkers (e.g. troponins, natriuretic peptides) have been studied for the detection of cardiotoxicity. Cardiac troponin levels are the gold standard biomarkers for the diagnosis of myocardial injury [68, 69]. In 2004 a study on troponin I in 703 breast cancer patients before and after chemotherapy showed that elevated troponin I levels were able to predict cardiovascular events. Further, patients with an early or persistent increase had a significant higher incidence of cardiac events (37\% versus $84 \%$ ) [70]. The same authors demonstrated that an increase in troponin I was a predictor of subsequent deterioration in LVEF in patients receiving high-dose chemotherapy [71]. However, another study in breast cancer patients failed to identify troponin I as early predictor of cardiac function [60]. Natriuretic peptides (e.g. N-terminal pro-BNP) reflect volume overload or increased wall stress. While increased BNP levels $(>100 \mathrm{pg} / \mathrm{mL}$ ) were able to predict congestive heart failure in a population of 333 patients undergoing anthracycline therapy [72], two other studies showed no correlation between natriuretic peptide levels and LVEF deterioration $[60,73]$. Reasons for inconsistent and conflicting results of studies using cardiac biomarkers include measurements in populations receiving different treatments, sample collections at varying time points, and the use of different cut-off values for "positive" biomarker values. However, in patients with elevated troponin more intensive monitoring may be recommended, while the ideal timing for troponin analysis and the cut-off for "positive" remain unclear.

Finally, microRNAs represent promising new approaches to predict cardiotoxicity. MicroRNAs such as miR-1 play an important role in the regulation of gene expression. Rigaud et al. demonstrated upregulated miR-1 levels in anthracycline treated breast cancer patients which were associated with future changes in LVEF "[74].

\section{A glimpse of treating cardiotoxicity}

The evidence for the treatment of cardiotoxic effects of cancer therapy is sparse. In 2652 patients treated with anthracyclines 226 patients developed cardiotoxicity (defined by a LVEF decrease of 10 percentage points to a value < $50 \%$ ). Heart failure therapy including ACE inhibitors and/ or beta-blockers was initiated early and $82 \%$ recovered from cardiotoxicity at least partially [13]. Based on this observational study in anthracycline therapy, the Working Group on Cardiooncology of the European Society of Cardiology recommends ACE inhibitors and beta-blockers in cancer patients with asymptomatic cardiac dysfunction to prevent the development of symptomatic heart failure or further dysfunction [5]. If LV function deteriorates during chemotherapy, the cardiooncology team has to balance between effective cancer therapy and cardiotoxicity. The recovery rate for trastuzumab-associated LV dysfunction is approximately $80 \%$ [75]. Thus, treatment should be suspended and re-evaluated after 3 weeks in the event of a reduction in the LVEF of $10 \%$ or more below $50 \%$. This is broadly in line with the current position paper of the ESC, which, however, recommends the continuation of the therapy in the presence of ACE inhibitors if the LVEF drops to values between 45 and $49 \%$ [5]. Therapy should be suspended and reevaluated after 3 weeks in the event of reduction in the LVEF of $10 \%$ to more below $50 \%$ [76]. 


\section{Other cardiovascular side effects caused by cancer therapies}

Beside myocardial dysfunction several cancer treatments predispose to cardiac arrhythmias [5]. Thus, an electrocardiogram (ECG) should be performed to identify ECG anomalies and cardiac arrhythmias. Some chemotherapeutic drugs (e.g. Tyrosine kinase inhibitors) may cause prolongation of the QT interval [5]. To avoid potentially life-threatening arrhythmias, frequency-corrected QT interval (QTc) should be assessed on a 12-lead ECG before initiation of cancer therapy and monitored under therapy. QTc intervals of $>500 \mathrm{~ms}$ or QTc prolongation of $>60 \mathrm{~ms}$ are at high risk for torsades de pointes tachyarrhythmias [77]. Atrial fibrillation (AF) and cancer go along with a state of hypercoagulability. In general, the risk of AF is increased in cancer patients. Cancer patients without a relevantly increased risk for bleeding (e.g. intracranial tumor, hematologic malignancies with coagulation defects, cancer therapy induced thrombocytopenia, severe metastatic hepatic disease etc.) should undergo the same considerations regarding anticoagulation as non-cancer patients [78]. Subgroup analyses of the direct oral anticoagulants (DOAC) have shown their safety and efficacy in cancer patients [79].

The risk for thromboembolic events is increased due to cancer itself but also as a consequence of chemotherapeutics and their administration routes affecting up to $20 \%$ of hospitalized patients [5]. For example, the combination of chemotherapy with VEGF inhibitors increase the risk of venous thromboembolism up to six-fold [80]. But also new therapeutic approaches as immunomodulatory drugs have been shown to significantly rise the thromboembolic risk [76]. Recent guidelines have incorporated DOACs into the actual treatment recommendations for venous thromboembolism - especially for patients with low bleeding risk who do not have gastrointestinal or genitourinary tract malignancies, severely depressed kidney function or relevant drugdrug interactions [81].

The ECG may also be indicative of myocardial ischemia. Mechanisms resulting in myocardial ischemia are manifold including vasospastic effects, endothelial injury, arterial occlusion, and defects in lipid metabolism. Typical ischemia-inducing drugs are Fluoropyrimidines (5-fluorouracil, capecitabine, gemcitabine), platinum compounds (cisplatin), and VEGF inhibitors (bevacizumab, sorafenib, sunitinib) [5]. If myocardial ischemia is suspected due to medical history and/or ECG, further work-up is important in those patients. But it must be acknowledged that the therapeutic options may be limited due to the restricted use of antiplatelet therapy in patients with (chemotherapy-induced) thrombocytopenia or increased bleeding risk. Platelet (PLT) number cut-offs for different antiplatelet regimens have been proposed (aspirin $>10,000$ PLT, aspirin+clopidogrel
$>30,000$ PLT, ticagrelor and prasugrel $>50,000$ PLT) [82]. Significantly reduced duration of dual antiplatelet therapy should be discussed in these cases. Close coordination between the oncologist and the cardiologist is crucial in these cases in an interdisciplinary team approach.

\section{Conclusion and perspective}

Careful baseline cardiac assessment and monitoring are essential in all patients receiving a potentially cardiotoxic anti-cancer therapy and are best realized in close cooperation between oncologist and cardiologist. Patients should be advised to be aware of the potential for acute and long-term cardiotoxicity and report symptoms to their health care provider. A cardiology consultation should be considered if the LVEF is $<53 \%$, GLS is below the limit of normal [83] and/ or troponin levels are elevated. Female survivors of childhood cancer should undergo cardiological screening before pregnancy. In addition to cardiac dysfunction, which is certainly the most common and most serious manifestation of cardiotoxicity, the risk of other manifestations such as cardiac arrhythmias, myocardial ischemia, thrombotic events, but also-especially after a long period of time after radiation-the occurrence of pericarditis and valve diseases must not to be disregarded. Currently, diagnostic and treatment algorithms in cardio-oncology are largely based on expert consensus. Further research is needed to assess long-term benefits of cardiac surveillance and effects of cardioprotective therapy.

Funding Open Access funding enabled and organized by Projekt DEAL.

Data availability Data sharing not applicable to this article as no datasets were generated or analysed during the current study.

Open Access This article is licensed under a Creative Commons Attribution 4.0 International License, which permits use, sharing, adaptation, distribution and reproduction in any medium or format, as long as you give appropriate credit to the original author(s) and the source, provide a link to the Creative Commons licence, and indicate if changes were made. The images or other third party material in this article are included in the article's Creative Commons licence, unless indicated otherwise in a credit line to the material. If material is not included in the article's Creative Commons licence and your intended use is not permitted by statutory regulation or exceeds the permitted use, you will need to obtain permission directly from the copyright holder. To view a copy of this licence, visit http://creativecommons.org/licenses/by/4.0/. 


\section{References}

1. Yeh ET, Chang HM (2016) Oncocardiology-past, present, and future: A review. JAMA Cardiol 1(9):1066-1072. https://doi.org/ 10.1001/jamacardio.2016.2132

2. Abdel-Qadir H, Austin PC, Lee DS, Amir E, Tu JV, Thavendiranathan P, Fung K, Anderson GM (2017) A population-based study of cardiovascular mortality following early-stage breast cancer. JAMA Cardiol 2(1):88-93. https://doi.org/10.1001/jamacardio. 2016.3841

3. Graffagnino J, Kondapalli L, Arora G, Hawi R, Lenneman CG (2020) Strategies to prevent cardiotoxicity. Curr Treat Options Oncol 21(4):32. https://doi.org/10.1007/s11864-020-0722-6

4. Ewer MS, Ewer SM (2015) Cardiotoxicity of anticancer treatments. Nat Rev Cardiol 12(9):547-558. https://doi.org/10.1038/ nrcardio.2015.65

5. Zamorano JL, Lancellotti P, Rodriguez Munoz D, Aboyans V, Asteggiano R, Galderisi M, Habib G, Lenihan DJ, Lip GYH, Lyon AR, Lopez Fernandez T, Mohty D, Piepoli MF, Tamargo J, Torbicki A, Suter TM, Group ESCSD (2016) 2016 ESC Position Paper on cancer treatments and cardiovascular toxicity developed under the auspices of the ESC Committee for Practice Guidelines: The Task Force for cancer treatments and cardiovascular toxicity of the European Society of Cardiology (ESC). Eur Heart J 37(36):2768-2801. https://doi.org/10.1093/eurheartj/ehw211

6. Oeffinger KC, Mertens AC, Sklar CA, Kawashima T, Hudson MM, Meadows AT, Friedman DL, Marina N, Hobbie W, KadanLottick NS, Schwartz CL, Leisenring W, Robison LL, Childhood Cancer Survivor S (2006) Chronic health conditions in adult survivors of childhood cancer. N Engl J Med 355(15):1572-1582. https://doi.org/10.1056/NEJMsa060185

7. Yu AF, Ky B (2016) Roadmap for biomarkers of cancer therapy cardiotoxicity. Heart 102(6):425-430. https://doi.org/10.1136/ heartjnl-2015-307894

8. Maurea N, Spallarossa P, Cadeddu C, Madonna R, Mele D, Monte I, Novo G, Pagliaro P, Pepe A, Tocchetti CG, Zito C, Mercuro G (2016) A recommended practical approach to the management of target therapy and angiogenesis inhibitors cardiotoxicity: an opinion paper of the working group on drug cardiotoxicity and cardioprotection, Italian Society of Cardiology. J Cardiovasc Med (Hagerstown) 17(Suppl 1):S93-S104. https://doi.org/10.2459/ JCM.0000000000000383

9. Abdel-Qadir H, Amir E, Thavendiranathan P (2016) Prevention, detection, and management of chemotherapy-related cardiac dysfunction. Can J Cardiol 32(7):891-899. https://doi.org/10.1016/j. cjca.2016.01.028

10. Yancy CW, Jessup M, Bozkurt B, Butler J, Casey DE Jr, Drazner MH, Fonarow GC, Geraci SA, Horwich T, Januzzi JL, Johnson MR, Kasper EK, Levy WC, Masoudi FA, McBride PE, McMurray JJ, Mitchell JE, Peterson PN, Riegel B, Sam F, Stevenson LW, Tang WH, Tsai EJ, Wilkoff BL, College A, of Cardiology F, American Heart Association Task Force on Practice G, (2013) 2013 ACCF/AHA guideline for the management of heart failure: a report of the American College of Cardiology Foundation/ American Heart Association Task Force on Practice Guidelines. J Am Coll Cardiol 62(16):e147-239. https://doi.org/10.1016/j.jacc. 2013.05.019

11. Plana JC, Galderisi M, Barac A, Ewer MS, Ky B, Scherrer-Crosbie M, Ganame J, Sebag IA, Agler DA, Badano LP, Banchs J, Cardinale D, Carver J, Cerqueira M, DeCara JM, Edvardsen T, Flamm SD, Force T, Griffin BP, Jerusalem G, Liu JE, Magalhaes A, Marwick T, Sanchez LY, Sicari R, Villarraga HR, Lancellotti $\mathrm{P}$ (2014) Expert consensus for multimodality imaging evaluation of adult patients during and after cancer therapy: a report from the American Society of Echocardiography and the European
Association of Cardiovascular Imaging. Eur Heart J Cardiovasc Imaging 15(10):1063-1093. https://doi.org/10.1093/ehjci/jeu192

12. Neilan TG, Jassal DS, Perez-Sanz TM, Raher MJ, Pradhan AD, Buys ES, Ichinose F, Bayne DB, Halpern EF, Weyman AE, Derumeaux G, Bloch KD, Picard MH, Scherrer-Crosbie M (2006) Tissue Doppler imaging predicts left ventricular dysfunction and mortality in a murine model of cardiac injury. Eur Heart $\mathbf{J}$ 27(15):1868-1875. https://doi.org/10.1093/eurheartj/ehl013

13. Cardinale D, Colombo A, Bacchiani G, Tedeschi I, Meroni CA, Veglia F, Civelli M, Lamantia G, Colombo N, Curigliano G, Fiorentini C, Cipolla CM (2015) Early detection of anthracycline cardiotoxicity and improvement with heart failure therapy. Circulation 131(22):1981-1988. https://doi.org/10.1161/CIRCULATIO NAHA.114.013777

14. Curigliano G, Cardinale D, Suter T, Plataniotis G, de Azambuja E, Sandri MT, Criscitiello C, Goldhirsch A, Cipolla C, Roila F, Group EGW (2012) Cardiovascular toxicity induced by chemotherapy, targeted agents and radiotherapy: ESMO Clinical Practice Guidelines. Ann Oncol 23 Suppl 7:vii155-166. doi:https://doi.org/ 10.1093/annonc/mds293

15. Meyer CC, Calis KA, Burke LB, Walawander CA, Grasela TH (1997) Symptomatic cardiotoxicity associated with 5-fluorouracil. Pharmacotherapy 17(4):729-736

16. Guglin M, Cutro R, Mishkin JD (2008) Trastuzumab-induced cardiomyopathy. J Card Fail 14(5):437-444. https://doi.org/10. 1016/j.cardfail.2008.02.002

17. Tarantini L, Cioffi G, Gori S, Tuccia F, Boccardi L, Bovelli D, Lestuzzi C, Maurea N, Oliva S, Russo G, Faggiano P, Italian Cardio-Oncologic N (2012) Trastuzumab adjuvant chemotherapy and cardiotoxicity in real-world women with breast cancer. J Card Fail 18(2):113-119. https://doi.org/10.1016/j.cardfail.2011.10.015

18. Mahmood SS, Fradley MG, Cohen JV, Nohria A, Reynolds KL, Heinzerling LM, Sullivan RJ, Damrongwatanasuk R, Chen CL, Gupta D, Kirchberger MC, Awadalla M, Hassan MZO, Moslehi JJ, Shah SP, Ganatra S, Thavendiranathan P, Lawrence DP, Groarke JD, Neilan TG (2018) Myocarditis in patients treated with immune checkpoint inhibitors. J Am Coll Cardiol 71(16):17551764. https://doi.org/10.1016/j.jacc.2018.02.037

19. Pfeffer TJ, Schlothauer S, Pietzsch S, Schaufelberger M, Auber B, Ricke-Hoch M, List M, Berliner D, Moulig VA, König T, Arany Z, Sliwa K, Bauersachs J, Hilfiker-Kleiner D (2019) Increased cancer prevalence in peripartum cardiomyopathy. JACC: CardioOncology 1(2):196-205. https://doi.org/10.1016/j. jaccao.2019.09.008

20. Thompson KA (2018) Pregnancy and Cardiomyopathy After Anthracyclines in Childhood. Front Cardiovasc Med 5:14. https://doi.org/10.3389/fcvm.2018.00014

21. Faber J, Wingerter A, Neu MA, Henninger N, Eckerle S, Munzel T, Lackner KJ, Beutel ME, Blettner M, Rathmann W, Peters A, Meisinger C, Linkohr B, Neuhauser H, Kaatsch P, Spix C, Schneider A, Merzenich H, Panova-Noeva M, Prochaska JH, Wild PS (2018) Burden of cardiovascular risk factors and cardiovascular disease in childhood cancer survivors: data from the German CVSS-study. Eur Heart J 39(17):1555-1562. https:// doi.org/10.1093/eurheartj/ehy026

22. Chow EJ, Chen Y, Kremer LC, Breslow NE, Hudson MM, Armstrong GT, Border WL, Feijen EA, Green DM, Meacham LR, Meeske KA, Mulrooney DA, Ness KK, Oeffinger KC, Sklar CA, Stovall M, van der Pal HJ, Weathers RE, Robison LL, Yasui Y (2015) Individual prediction of heart failure among childhood cancer survivors. J Clin Oncol 33(5):394-402. https://doi.org/ 10.1200/JCO.2014.56.1373

23. Mulder RL, Kremer LC, Hudson MM, Bhatia S, Landier W, Levitt G, Constine LS, Wallace WH, van Leeuwen FE, Ronckers CM, Henderson TO, Dwyer M, Skinner R, Oeffinger $\mathrm{KC}$, International Late Effects of Childhood Cancer Guideline 
Harmonization G (2013) Recommendations for breast cancer surveillance for female survivors of childhood, adolescent, and young adult cancer given chest radiation: a report from the International Late Effects of Childhood Cancer Guideline Harmonization Group. Lancet Oncol 14(13):e621-629. https:// doi.org/10.1016/S1470-2045(13)70303-6

24. Chow EJ, Chen Y, Hudson MM, Feijen EAM, Kremer LC, Border WL, Green DM, Meacham LR, Mulrooney DA, Ness KK, Oeffinger KC, Ronckers CM, Sklar CA, Stovall M, van der Pal HJ, van Dijk I, van Leeuwen FE, Weathers RE, Robison LL, Armstrong GT, Yasui Y (2018) Prediction of ischemic heart disease and stroke in survivors of childhood cancer. J Clin Oncol 36(1):44-52. https://doi.org/10.1200/JCO.2017.74.8673

25. Mulrooney DA, Nunnery SE, Armstrong GT, Ness KK, Srivastava D, Donovan FD, Kurt BA, Metzger ML, Krasin MJ, Joshi V, Durand JB, Robison LL, Hudson MM, Flamm SD (2014) Coronary artery disease detected by coronary computed tomography angiography in adult survivors of childhood Hodgkin lymphoma. Cancer 120(22):3536-3544. https://doi.org/10.1002/ cncr.28925

26. Chang HM, Okwuosa TM, Scarabelli T, Moudgil R, Yeh ETH (2017) Cardiovascular complications of cancer therapy: Best practices in diagnosis, prevention, and management: Part 2. J Am Coll Cardiol 70(20):2552-2565. https://doi.org/10.1016/j.jacc.2017.09. 1095

27. Totzeck M, Schuler M, Stuschke M, Heusch G, Rassaf T (2019) Cardio-oncology - strategies for management of cancer-therapy related cardiovascular disease. Int J Cardiol 280:163-175. https:// doi.org/10.1016/j.ijcard.2019.01.038

28. McGale P, Darby SC, Hall P, Adolfsson J, Bengtsson NO, Bennet AM, Fornander T, Gigante B, Jensen MB, Peto R, Rahimi K, Taylor CW, Ewertz M (2011) Incidence of heart disease in 35,000 women treated with radiotherapy for breast cancer in Denmark and Sweden. Radiother Oncol 100(2):167-175. https://doi.org/ 10.1016/j.radonc.2011.06.016

29. Darby SC, Ewertz M, McGale P, Bennet AM, Blom-Goldman U, Bronnum D, Correa C, Cutter D, Gagliardi G, Gigante B, Jensen MB, Nisbet A, Peto R, Rahimi K, Taylor C, Hall P (2013) Risk of ischemic heart disease in women after radiotherapy for breast cancer. N Engl J Med 368(11):987-998. https://doi.org/10.1056/ NEJMoa1209825

30. Taylor C, Correa C, Duane FK, Aznar MC, Anderson SJ, Bergh J, Dodwell D, Ewertz M, Gray R, Jagsi R, Pierce L, Pritchard KI, Swain S, Wang Z, Wang Y, Whelan T, Peto R, McGale P, Collaborative EBCT, G, (2017) Estimating the risks of breast cancer radiotherapy: Evidence from modern radiation doses to the lungs and heart and from previous randomized trials. J Clin Oncol 35(15):1641-1649. https://doi.org/10.1200/JCO.2016.72. 0722

31. Wolchok JD (2015) PD-1 Blockers. Cell 162(5):937. https://doi. org/10.1016/j.cell.2015.07.045

32. Ribas A, Wolchok JD (2018) Cancer immunotherapy using checkpoint blockade. Science 359(6382):1350-1355. https://doi.org/10. 1126/science.aar4060

33. Escudier M, Cautela J, Malissen N, Ancedy Y, Orabona M, Pinto J, Monestier S, Grob JJ, Scemama U, Jacquier A, Lalevee N, Barraud J, Peyrol M, Laine M, Bonello L, Paganelli F, Cohen A, Barlesi F, Ederhy S, Thuny F (2017) Clinical features, management, and outcomes of immune checkpoint inhibitor-related cardiotoxicity. Circulation 136(21):2085-2087. https://doi.org/10. 1161/CIRCULATIONAHA.117.030571

34. Moslehi JJ, Johnson DB, Sosman JA (2017) Myocarditis with Immune Checkpoint Blockade. N Engl J Med 376(3):292. https:// doi.org/10.1056/NEJMc1615251

35. Moslehi JJ, Salem JE, Sosman JA, Lebrun-Vignes B, Johnson DB (2018) Increased reporting of fatal immune checkpoint inhibitor-associated myocarditis. Lancet 391(10124):933. https:// doi.org/10.1016/S0140-6736(18)30533-6

36. Salem JE, Manouchehri A, Moey M, Lebrun-Vignes B, Bastarache L, Pariente A, Gobert A, Spano JP, Balko JM, Bonaca MP, Roden DM, Johnson DB, Moslehi JJ (2018) Cardiovascular toxicities associated with immune checkpoint inhibitors: an observational, retrospective, pharmacovigilance study. Lancet Oncol 19(12):1579-1589. https://doi.org/10.1016/S1470-2045(18) 30608-9

37. Hohmann C, Baldus S, Pfister R (2019) Curing cancer and protecting the heart: Challenges in cardio-oncology in the era of modern tumor treatment. Herz 44(2):175-188. https://doi.org/10. 1007/s00059-019-4787-6

38. Martinez-Calle N, Rodriguez-Otero P, Villar S, Mejias L, Melero I, Prosper F, Marinello P, Paiva B, Idoate M, San-Miguel J (2018) Anti-PD1 associated fulminant myocarditis after a single pembrolizumab dose: the role of occult pre-existing autoimmunity. Haematologica 103(7):e318-e321. https://doi.org/10.3324/haema tol.2017.185777

39. Bockstahler M, Fischer A, Goetzke CC, Neumaier HL, Sauter M, Kespohl M, Muller AM, Meckes C, Salbach C, Schenk M, Heuser A, Landmesser U, Weiner J, Meder B, Lehmann L, Kratzer A, Klingel K, Katus HA, Kaya Z, Beling A (2020) Heart-specific immune responses in an animal model of autoimmune-related myocarditis mitigated by an immunoproteasome inhibitor and genetic ablation. Circulation 141(23):1885-1902. https://doi.org/ 10.1161/CIRCULATIONAHA.119.043171

40. Mirabel M, Callon D, Bruneval P, Lebreil A-L, Mousseaux E, Oudard S, Hulot J-S, Andreoletti L (2020) Late-onset giant cell myocarditis due to enterovirus during treatment with immune checkpoint inhibitors. JACC CardioOncology 2(3):511-514. https://doi.org/10.1016/j.jaccao.2020.05.022

41. Brahmer JR, Lacchetti C, Schneider BJ, Atkins MB, Brassil KJ, Caterino JM, Chau I, Ernstoff MS, Gardner JM, Ginex P, Hallmeyer S, Holter Chakrabarty J, Leighl NB, Mammen JS, McDermott DF, Naing A, Nastoupil LJ, Phillips T, Porter LD, Puzanov I, Reichner CA, Santomasso BD, Seigel C, Spira A, Suarez-Almazor ME, Wang Y, Weber JS, Wolchok JD, Thompson JA, National Comprehensive Cancer N (2018) Management of immune-related adverse events in patients treated with immune checkpoint inhibitor therapy: American society of clinical oncology clinical practice guideline. J Clin Oncol 36(17):1714-1768. https://doi.org/10.1200/JCO.2017.77.6385

42. Kwon HJ, Cote TR, Cuffe MS, Kramer JM, Braun MM (2003) Case reports of heart failure after therapy with a tumor necrosis factor antagonist. Ann Intern Med 138(10):807-811. https://doi. org/10.7326/0003-4819-138-10-200305200-00008

43. Waliany S, Lee D, Witteles RM, Neal JW, Nguyen P, Davis MM, Salem JE, Wu SM, Moslehi JJ, Zhu H (2021) Immune checkpoint inhibitor cardiotoxicity: Understanding basic mechanisms and clinical characteristics and finding a cure. Annu Rev Pharmacol Toxicol 61:113-134. https://doi.org/10.1146/annurev-pharm tox-010919-023451

44. Salem JE, Allenbach Y, Vozy A, Brechot N, Johnson DB, Moslehi JJ, Kerneis M (2019) Abatacept for severe immune checkpoint inhibitor-associated myocarditis. N Engl J Med 380(24):23772379. https://doi.org/10.1056/NEJMc1901677

45. Al-Kindi SG, Oliveira GH (2016) Incidence and trends of cardiovascular mortality after common cancers in young adults: Analysis of surveillance, epidemiology and end-results program. World J Cardiol 8(6):368-374. https://doi.org/10.4330/wjc.v8.i6.368

46. Mehta LS, Watson KE, Barac A, Beckie TM, Bittner V, CruzFlores S, Dent S, Kondapalli L, Ky B, Okwuosa T, Pina IL, Volgman AS, American Heart Association Cardiovascular Disease in W, Special Populations Committee of the Council on Clinical C, Council on C, Stroke N, Council on Quality of C, Outcomes 
R (2018) Cardiovascular disease and breast cancer: where these entities intersect: A scientific statement from the american heart association. Circulation 137(8):e30-e66. https://doi.org/10.1161/ CIR.0000000000000556

47. Al-Kindi SG, Oliveira GH (2016) Prevalence of preexisting cardiovascular disease in patients with different types of cancer: the unmet need for onco-cardiology. Mayo Clin Proc 91(1):81-83. https://doi.org/10.1016/j.mayocp.2015.09.009

48. Armstrong GT, Kawashima T, Leisenring W, Stratton K, Stovall M, Hudson MM, Sklar CA, Robison LL, Oeffinger KC (2014) Aging and risk of severe, disabling, life-threatening, and fatal events in the childhood cancer survivor study. J Clin Oncol 32(12):1218-1227. https://doi.org/10.1200/JCO.2013.51.1055

49. Jawa Z, Perez RM, Garlie L, Singh M, Qamar R, Khandheria BK, Jahangir A, Shi Y (2016) Risk factors of trastuzumab-induced cardiotoxicity in breast cancer: A meta-analysis. Medicine (Baltimore) 95(44):e5195. https://doi.org/10.1097/MD.0000000000 005195

50. Meyer RM, Gospodarowicz MK, Connors JM, Pearcey RG, Wells WA, Winter JN, Horning SJ, Dar AR, Shustik C, Stewart DA, Crump M, Djurfeldt MS, Chen BE, Shepherd LE, Group NCT, Eastern Cooperative Oncology G (2012) ABVD alone versus radiation-based therapy in limited-stage Hodgkin's lymphoma. N Engl J Med 366(5):399-408. https://doi.org/10.1056/NEJMo a1111961

51. Lancellotti P, Nkomo VT, Badano LP, Bergler-Klein J, Bogaert J, Davin L, Cosyns B, Coucke P, Dulgheru R, Edvardsen T, Gaemperli O, Galderisi M, Griffin B, Heidenreich PA, Nieman K, Plana JC, Port SC, Scherrer-Crosbie M, Schwartz RG, Sebag IA, Voigt JU, Wann S, Yang PC, European Society of Cardiology Working Groups on Nuclear C, Cardiac Computed T, Cardiovascular Magnetic R, American Society of Nuclear C, Society for Cardiovascular Magnetic R, Society of Cardiovascular Computed T (2013) Expert consensus for multi-modality imaging evaluation of cardiovascular complications of radiotherapy in adults: a report from the European Association of Cardiovascular Imaging and the American Society of Echocardiography. Eur Heart J Cardiovasc Imaging 14(8):721-740. https://doi.org/10.1093/ehjci/jet123

52. Lyon AR, Dent S, Stanway S, Earl H, Brezden-Masley C, CohenSolal A, Tocchetti CG, Moslehi JJ, Groarke JD, Bergler-Klein J, Khoo V, Tan LL, Anker MS, von Haehling S, Maack C, Pudil R, Barac A, Thavendiranathan P, Ky B, Neilan TG, Belenkov Y, Rosen SD, Iakobishvili Z, Sverdlov AL, Hajjar LA, Macedo AVS, Manisty C, Ciardiello F, Farmakis D, de Boer RA, Skouri H, Suter TM, Cardinale D, Witteles RM, Fradley MG, Herrmann J, Cornell RF, Wechelaker A, Mauro MJ, Milojkovic D, de Lavallade H, Ruschitzka F, Coats AJS, Seferovic PM, Chioncel O, Thum T, Bauersachs J, Andres MS, Wright DJ, Lopez-Fernandez T, Plummer C, Lenihan D (2020) Baseline cardiovascular risk assessment in cancer patients scheduled to receive cardiotoxic cancer therapies: a position statement and new risk assessment tools from the Cardio-Oncology Study Group of the Heart Failure Association of the European Society of Cardiology in collaboration with the International Cardio-Oncology Society. Eur J Heart Fail 22(11):1945-1960. https://doi.org/10.1002/ejhf.1920

53. Berliner D, Beutel G, Bauersachs J (2020) Echocardiography and biomarkers for the diagnosis of cardiotoxicity. Herz 45(7):637644. https://doi.org/10.1007/s00059-020-04957-5

54. Thavendiranathan P, Grant AD, Negishi T, Plana JC, Popovic ZB, Marwick TH (2013) Reproducibility of echocardiographic techniques for sequential assessment of left ventricular ejection fraction and volumes: application to patients undergoing cancer chemotherapy. J Am Coll Cardiol 61(1):77-84. https://doi.org/10. 1016/j.jacc.2012.09.035

55. Badano LP, Boccalini F, Muraru D, Bianco LD, Peluso D, Bellu R, Zoppellaro G, Iliceto S (2012) Current clinical applications of transthoracic three-dimensional echocardiography. Journal of cardiovascular ultrasound 20(1):1-22. https://doi.org/10.4250/jcu. 2012.20.1.1

56. Lang RM, Badano LP, Mor-Avi V, Afilalo J, Armstrong A, Ernande L, Flachskampf FA, Foster E, Goldstein SA, Kuznetsova T, Lancellotti P, Muraru D, Picard MH, Rietzschel ER, Rudski L, Spencer KT, Tsang W, Voigt J-U (2015) Recommendations for cardiac chamber quantification by echocardiography in adults: An update from the American society of echocardiography and the European association of cardiovascular imaging. European Heart Journal - Cardiovascular Imaging 16(3):233-271. https://doi.org/ 10.1093/ehjci/jev014

57. Armenian SH, Lacchetti C, Barac A, Carver J, Constine LS, Denduluri N, Dent S, Douglas PS, Durand JB, Ewer M, Fabian C, Hudson M, Jessup M, Jones LW, Ky B, Mayer EL, Moslehi J, Oeffinger K, Ray K, Ruddy K, Lenihan D (2017) Prevention and monitoring of cardiac dysfunction in survivors of adult cancers: American society of clinical oncology clinical practice guideline. J Clin Oncol 35(8):893-911. https://doi.org/10.1200/JCO.2016. 70.5400

58. Ewer MS, Ali MK, Mackay B, Wallace S, Valdivieso M, Legha SS, Benjamin RS, Haynie TP (1984) A comparison of cardiac biopsy grades and ejection fraction estimations in patients receiving Adriamycin. J Clin Oncol 2(2):112-117. https://doi.org/10. 1200/JCO.1984.2.2.112

59. Sawaya H, Sebag IA, Plana JC, Januzzi JL, Ky B, Tan TC, Cohen V, Banchs J, Carver JR, Wiegers SE, Martin RP, Picard MH, Gerszten RE, Halpern EF, Passeri J, Kuter I, Scherrer-Crosbie M (2012) Assessment of echocardiography and biomarkers for the extended prediction of cardiotoxicity in patients treated with anthracyclines, taxanes, and trastuzumab. Circ Cardiovasc Imaging 5(5):596-603. https://doi.org/10.1161/CIRCIMAGING.112. 973321

60. Fallah-Rad N, Walker JR, Wassef A, Lytwyn M, Bohonis S, Fang T, Tian G, Kirkpatrick ID, Singal PK, Krahn M, Grenier D, Jassal DS (2011) The utility of cardiac biomarkers, tissue velocity and strain imaging, and cardiac magnetic resonance imaging in predicting early left ventricular dysfunction in patients with human epidermal growth factor receptor II-positive breast cancer treated with adjuvant trastuzumab therapy. J Am Coll Cardiol 57(22):2263-2270. https://doi.org/10.1016/j.jacc.2010.11.063

61. Negishi T, Negishi K, Thavendiranathan P, Cho GY, Popescu BA, Vinereanu D, Kurosawa K, Penicka M, Marwick TH, Investigators S (2017) Effect of experience and training on the concordance and precision of strain measurements. JACC Cardiovasc Imaging 10(5):518-522. https://doi.org/10.1016/j.jcmg.2016.06.012

62. Thavendiranathan P, Poulin F, Lim K-D, Plana JC, Woo A, Marwick TH (2014) Use of myocardial strain imaging by echocardiography for the early detection of cardiotoxicity in patients during and after cancer chemotherapy: A systematic review. J Am Coll Cardiol 63(25):2751-2768. https://doi.org/10.1016/j.jacc.2014. 01.073

63. Awadalla M, Mahmood SS, Groarke JD, Hassan MZO, Nohria A, Rokicki A, Murphy SP, Mercaldo ND, Zhang L, Zlotoff DA, Reynolds KL, Alvi RM, Banerji D, Liu S, Heinzerling LM, JonesO'Connor M, Bakar RB, Cohen JV, Kirchberger MC, Sullivan RJ, Gupta D, Mulligan CP, Shah SP, Ganatra S, Rizvi MA, Sahni G, Tocchetti CG, Lawrence DP, Mahmoudi M, Devereux RB, Forrestal BJ, Mandawat A, Lyon AR, Chen CL, Barac A, Hung J, Thavendiranathan P, Picard MH, Thuny F, Ederhy S, Fradley MG, Neilan TG (2020) Global longitudinal strain and cardiac events in patients with immune checkpoint inhibitor-related myocarditis. J Am Coll Cardiol 75(5):467-478. https://doi.org/10.1016/j.jacc. 2019.11.049

64. Seraphim A, Westwood M, Bhuva AN, Crake T, Moon JC, Menezes LJ, Lloyd G, Ghosh AK, Slater S, Oakervee H, Manisty CH 
(2019) Advanced imaging modalities to monitor for cardiotoxicity. Curr Treat Options Oncol 20(9):73. https://doi.org/10.1007/ s11864-019-0672-z

65. Cau R, Bassareo P, Cherchi V, Palmisano V, Suri JS, Porcu M, Balestrieri A, Pontone G, Saba L (2020) Early diagnosis of chemotherapy-induced cardiotoxicity by cardiac MRI. Eur J Radiol. https://doi.org/10.1016/j.ejrad.2020.109158

66. Čelutkienè J, Pudil R, López-Fernández T, Grapsa J, Nihoyannopoulos P, Bergler-Klein J, Cohen-Solal A, Farmakis D, Tocchetti CG, von Haehling S, Barberis V, Flachskampf FA, Čeponienė I, Haegler-Laube E, Suter T, Lapinskas T, Prasad S, de Boer RA, Wechalekar K, Anker MS, Iakobishvili Z, Bucciarelli-Ducci C, Schulz-Menger J, Cosyns B, Gaemperli O, Belenkov Y, Hulot J-S, Galderisi M, Lancellotti P, Bax J, Marwick TH, Chioncel O, Jaarsma T, Mullens W, Piepoli M, Thum T, Heymans S, Mueller C, Moura B, Ruschitzka F, Zamorano JL, Rosano G, Coats AJS, Asteggiano R, Seferovic P, Edvardsen T, Lyon AR (2020) Role of cardiovascular imaging in cancer patients receiving cardiotoxic therapies: a position statement on behalf of the Heart Failure Association (HFA), the European Association of Cardiovascular Imaging (EACVI) and the Cardio-Oncology Council of the European Society of Cardiology (ESC). Eur J Heart Fail 22(9):1504-1524. https://doi.org/10.1002/ejhf.1957

67. Galán-Arriola C, Lobo M, Vílchez-Tschischke JP, López GJ, de Molina-Iracheta A, Pérez-Martínez C, Agüero J, FernándezJiménez R, Martín-García A, Oliver E, Villena-Gutierrez R, Pizarro G, Sánchez PL, Fuster V, Sánchez-González J, Ibanez B (2019) Serial magnetic resonance imaging to identify early stages of anthracycline-induced cardiotoxicity. J Am Coll Cardiol 73(7):779-791. https://doi.org/10.1016/j.jacc.2018.11.046

68. Reichlin T, Hochholzer W, Bassetti S, Steuer S, Stelzig C, Hartwiger S, Biedert S, Schaub N, Buerge C, Potocki M, Noveanu M, Breidthardt T, Twerenbold R, Winkler K, Bingisser R, Mueller C (2009) Early diagnosis of myocardial infarction with sensitive cardiac troponin assays. N Engl J Med 361(9):858-867. https:// doi.org/10.1056/NEJMoa0900428

69. Wright RS, Anderson JL, Adams CD, Bridges CR, Casey DE Jr, Ettinger SM, Fesmire FM, Ganiats TG, Jneid H, Lincoff AM, Peterson ED, Philippides GJ, Theroux P, Wenger NK, Zidar JP, Anderson JL, Adams CD, Antman EM, Bridges CR, Califf RM, Casey DE Jr, Chavey WE 2nd, Fesmire FM, Hochman JS, Levin TN, Lincoff AM, Peterson ED, Theroux P, Wenger NK, Zidar JP, College A, of Cardiology Foundation, American Heart Association Task Force on Practice G, (2011) 2011 ACCF/AHA focused update incorporated into the ACC/AHA 2007 Guidelines for the Management of Patients with Unstable Angina/Non-ST-Elevation Myocardial Infarction: a report of the American College of Cardiology Foundation/American Heart Association Task Force on Practice Guidelines developed in collaboration with the American Academy of Family Physicians, Society for Cardiovascular Angiography and Interventions, and the Society of Thoracic Surgeons. J Am Coll Cardiol 57(19):e215-367. https://doi.org/10.1016/j. jacc.2011.02.011

70. Cardinale D, Sandri MT, Colombo A, Colombo N, Boeri M, Lamantia G, Civelli M, Peccatori F, Martinelli G, Fiorentini C, Cipolla CM (2004) Prognostic value of troponin I in cardiac risk stratification of cancer patients undergoing high-dose chemotherapy. Circulation 109(22):2749-2754. https://doi.org/10.1161/01. CIR.0000130926.51766.CC

71. Cardinale D, Sandri MT, Martinoni A, Tricca A, Civelli M, Lamantia G, Cinieri S, Martinelli G, Cipolla CM, Fiorentini C (2000) Left ventricular dysfunction predicted by early troponin I release after high-dose chemotherapy. J Am Coll Cardiol 36(2):517-522. https://doi.org/10.1016/s0735-1097(00)00748-8

72. Skovgaard D, Hasbak P, Kjaer A (2014) BNP predicts chemotherapy-related cardiotoxicity and death: comparison with gated equilibrium radionuclide ventriculography. PLoS ONE 9(5):e96736. https://doi.org/10.1371/journal.pone.0096736

73. Ky B, Putt M, Sawaya H, French B, Januzzi JL Jr, Sebag IA, Plana JC, Cohen V, Banchs J, Carver JR, Wiegers SE, Martin RP, Picard MH, Gerszten RE, Halpern EF, Passeri J, Kuter I, ScherrerCrosbie M (2014) Early increases in multiple biomarkers predict subsequent cardiotoxicity in patients with breast cancer treated with doxorubicin, taxanes, and trastuzumab. J Am Coll Cardiol 63(8):809-816. https://doi.org/10.1016/j.jacc.2013.10.061

74. Rigaud VO, Ferreira LR, Ayub-Ferreira SM, Avila MS, Brandao SM, Cruz FD, Santos MH, Cruz CB, Alves MS, Issa VS, Guimaraes GV, Cunha-Neto E, Bocchi EA (2017) Circulating miR-1 as a potential biomarker of doxorubicin-induced cardiotoxicity in breast cancer patients. Oncotarget 8(4):6994-7002. https://doi. org/10.18632/oncotarget.14355

75. Yoon HJ, Kim KH, Kim HY, Park H, Cho JY, Hong YJ, Park HW, Kim JH, Ahn Y, Jeong MH, Cho JG, Park JC (2019) Impacts of non-recovery of trastuzumab-induced cardiomyopathy on clinical outcomes in patients with breast cancer. Clin Res Cardiol 108(8):892-900. https://doi.org/10.1007/s00392-019-01417-x

76. Rassaf T, Totzeck M, Backs J, Bokemeyer C, Hallek M, HilfikerKleiner D, Hochhaus A, Luftner D, Muller OJ, Neudorf U, Pfister R, von Haehling S, Lehmann LH, Bauersachs J, Committee for Clinical Cardiovascular Medicine of the German Cardiac S (2020) Onco-cardiology: Consensus paper of the german cardiac society, the german society for pediatric cardiology and congenital heart defects and the german society for hematology and medical oncology. Clin Res Cardiol 109(10):1197-1222. https://doi.org/ 10.1007/s00392-020-01636-7

77. Priori SG, Blomstrom-Lundqvist C, Mazzanti A, Blom N, Borggrefe M, Camm J, Elliott PM, Fitzsimons D, Hatala R, Hindricks G, Kirchhof P, Kjeldsen K, Kuck KH, Hernandez-Madrid A, Nikolaou N, Norekval TM, Spaulding C, Van Veldhuisen DJ, Group ESCSD (2015) 2015 ESC Guidelines for the management of patients with ventricular arrhythmias and the prevention of sudden cardiac death: The Task Force for the Management of Patients with Ventricular Arrhythmias and the Prevention of Sudden Cardiac Death of the European Society of Cardiology (ESC). Endorsed by: Association for European Paediatric and Congenital Cardiology (AEPC). Eur Heart J 36 (41):2793-2867. doi:https:// doi.org/10.1093/eurheartj/ehv316

78. Farmakis D, Parissis J, Filippatos G (2014) Insights into oncocardiology: atrial fibrillation in cancer. J Am Coll Cardiol 63(10):945-953. https://doi.org/10.1016/j.jacc.2013.11.026

79. Bisceglia I, Cartoni D, Petrolati S (2020) Concepts in cardiac oncology. European Heart Journal Supplements 22:L19-L23. https://doi.org/10.1093/eurheartj/suaa127

80. Haddad TC, Greeno EW (2006) Chemotherapy-induced thrombosis. Thromb Res 118(5):555-568. https://doi.org/10.1016/j.throm res.2005.10.015

81. Streiff MB, Abutalib SA, Farge D, Murphy M, Connors JM, Piazza G (2020) Update on guidelines for the management of cancer-associated thrombosis. Oncologist. https://doi.org/10.1002/ onco. 13596

82. Iliescu CA, Grines CL, Herrmann J, Yang EH, Cilingiroglu M, Charitakis K, Hakeem A, Toutouzas KP, Leesar MA, Marmagkiolis K (2016) SCAI Expert consensus statement: Evaluation, management, and special considerations of cardio-oncology patients in the cardiac catheterization laboratory (endorsed by the cardiological society of india, and sociedad Latino Americana de Cardiologia intervencionista). Catheter Cardiovasc Interv 87(5):E202-E223. https://doi.org/10.1002/ccd.26379

83. Takigiku K, Takeuchi M, Izumi C, Yuda S, Sakata K, Ohte N, Tanabe K, Nakatani S, investigators J, (2012) Normal range of left ventricular 2-dimensional strain: Japanese Ultrasound 
Speckle Tracking of the Left Ventricle (JUSTICE) study. Circ J 76(11):2623-2632. https://doi.org/10.1253/circj.cj-12-0264

84. Chung R, Ghosh AK, Banerjee A (2018) Cardiotoxicity: precision medicine with imprecise definitions. Open Heart 5(2):e000774. https://doi.org/10.1136/openhrt-2018-000774

85. Virani SA, Dent S, Brezden-Masley C, Clarke B, Davis MK, Jassal DS, Johnson C, Lemieux J, Paterson I, Sebag IA, Simmons C, Sulpher J, Thain K, Thavendiranathan P, Wentzell JR, Wurtele N, Cote MA, Fine NM, Haddad H, Hayley BD, Hopkins S, Joy AA, Rayson D, Stadnick E, Straatman L (2016) Canadian cardiovascular society guidelines for evaluation and management of cardiovascular complications of cancer therapy. Can J Cardiol 32(7):831-841. https://doi.org/10.1016/j.cjca.2016.02.078

86. Curigliano G, Lenihan D, Fradley M, Ganatra S, Barac A, Blaes A, Herrmann J, Porter C, Lyon AR, Lancellotti P, Patel A, DeCara
J, Mitchell J, Harrison E, Moslehi J, Witteles R, Calabro MG, Orecchia R, de Azambuja E, Zamorano JL, Krone R, Iakobishvili Z, Carver J, Armenian S, Ky B, Cardinale D, Cipolla CM, Dent S, Jordan K (2020) Management of cardiac disease in cancer patients throughout oncological treatment: ESMO consensus recommendations. Ann Oncol 31(2):171-190. https://doi.org/10. 1016/j.annonc.2019.10.023

Publisher's Note Springer Nature remains neutral with regard to jurisdictional claims in published maps and institutional affiliations. 